\title{
Goblet cell carcinoid of the appendix accompanied by adenomatous polyp with high-grade dysplasia at the cecum
}

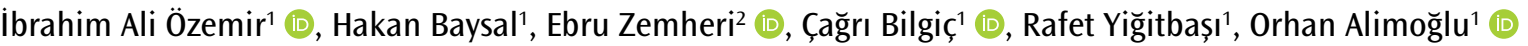

\section{ABSTRACT}

Goblet cell carcinoid tumor of the appendix is an uncommon neoplasia that shares the histological attributes of both adenocarcinoma and carcinoid tumors. Its prognosis has a more aggressive course than the other known carcinoid tumors. Clinical diagnosis of goblet cell carcinoid is seldom made preoperatively. The most common clinical presentation of goblet cell carcinoid tumor is acute appendicitis. In this study, we report a patient on whom right hemicolectomy was performed because of a cacal sessile polyp with high grade dysplasia; goblet cell carcinoid tumor of the appendix was revealed incidentally during microscopic evaluation of the appendectomy specimen. The patient healed uneventfully and no recurrence was observed after the 12-month follow-up period. Careful microscopic examination of the appendectomy specimen is key for the diagnosis of appendiceal tumors such as goblet cell carcinoid, especially in elderly patients.

Keywords: Goblet cell carcinoid, appendix, adenomatous polyp
\end{abstract}

ORCID IDs of the authors:

I.A.0. 0000-0001-8693-9358;

E.Z. 0000-0003-0247-0332;

C.B. $0000-0002-4006-1583$;

0.A. 0000-0003-2130-2529.

Cite this paper as:

Özemir İA, Baysal H,

Zemheri E, Bilgiç $C$

Yiğitbaşı R, Alimoğlu 0.

Goblet cell carcinoid of the

appendix accompanied by

adenomatous polyp with

high-grade dysplasia at the

cecum. Turk J Surg 201834

(3): 234-236

'Department of General Surgery, İstanbul Medeniyet University School of Medicine, Göztepe Training and Research Hospital, İstanbul, Turkey

2Department of Pathology, İstanbul Medeniyet University School of Medicine, Göztepe Training and Research Hospital, İstanbul, Turkey

\section{Corresponding Author} İbrahim Ali Özemir e-mail:draliozemir@hotmail.com

Received: 26.08.2015

Accepted: 16.11.2015

Available Online Date: 03.01.2018

CCopyright 2018

by Turkish Surgical Association

Available online at

www.turkjsurg.com

\section{INTRODUCTION}

Primary appendiceal tumors are detected in $0.9 \%-1.4 \%$ of all appendectomy specimens (1). Since carcinoid tumor was first described by Merling (2) in 1838, three different histological subtypes have been described: argentaffin-positive carcinoid; non-argentaffin carcinoid; and goblet cell carcinoid (GCC) (3). GCC shows attributes of both carcinoid tumor and adenocarcinoma. GCC constitutes less than $5 \%$ of primary appendix tumors, and the mean age for GCC was determined to be 58.9 years $(4,5)$. Because its behavior is more aggressive than that of the other standard carcinoid tumors, more extensive surgical approaches may be required (6). A five-year survey revealed a survival rate of $60 \%-84 \%$ (7). Metastatic disease develops in approximately $20 \%$ of patients. GCC of the appendix has various clinical presentations ranging from asymptomatic to acute appendicitis, which is the most common presentation; toward the other end of the spectrum, metastatic presentations such as Krukenberg's tumor or peritoneal carcinomatosis can be observed. Acute appendicitis occurs due to luminal stenosis of the appendix (8). Other clinical presentations of GCCs are lower abdomen pain, gastrointestinal bleeding, and palpable mass $(8,9)$. In this study, a rare combination of GCC of the appendix and high grade displasia polyp of the cecum is reported with a review of the relevant literature.

\section{CASE PRESENTATION}

A 46-year-old female patient was admitted to our surgical department with complaints of rectal bleeding, weakness, and fatigue. Her physical examination was unremarkable. Neither hemorrhoid nor anal fissure was detected upon anorectal examination, and her anal sphincter tone was normal. No palpable mass was detected upon rectal digital examination. Laboratory tests were as follows: hemoglobin: 10.1 $\mathrm{g} / \mathrm{dL}$, hematocrit: $32 \%$, leukocyte: $12.000 \mathrm{~K} / \mathrm{mm}^{3}$, and platelet: $247.000 \mathrm{~K} / \mathrm{mm}^{3}$. Colonoscopy was performed to determine the source of the bleeding. Colonoscopy revealed a sessile polyp $3 \mathrm{~cm}$ in diameter at the distal part of the cecum. The patient underwent hot snare polypectomy, and the sessile polyp was partially resected piecemeal. The pathological assessment of the specimen showed adenomatous polyps with high-grade dysplasia, and the surgical margin was positive. Abdominal tomography was unremarkable; neither abdominal tumoral lesion nor metastatic lesion was detected. Serum CA19-9 and CEA levels were found to be $12.25 \mathrm{U} / \mathrm{mL}$ and $1.98 \mathrm{ng} / \mathrm{mL}$, respectively. Right hemicolectomy and endto-side ileotransversostomy were performed on the patient. Intraluminal rigid and irregular areas that did not extend beyond the serosa were palpated in the cecum. No other intra-abdominal pathologic findings were detected during surgery. The patient healed uneventfully, and no complications occurred.

The pathological analysis of the specimen revealed a 1-cm-long adenovillous polyp with high-grade displasia in the distal part of the cecum. Focal hemorrhage and edema areas were observed in the cecal mucosa. No tumoral lesion was detected in the cecum except for a remnant of the polyp. The serosal surface of the appendix was hyperemic, and its lumen was of obliterated appearance in the section. Tumoral infiltration to all layers of the appendix wall expanding through the periappendicular area was 


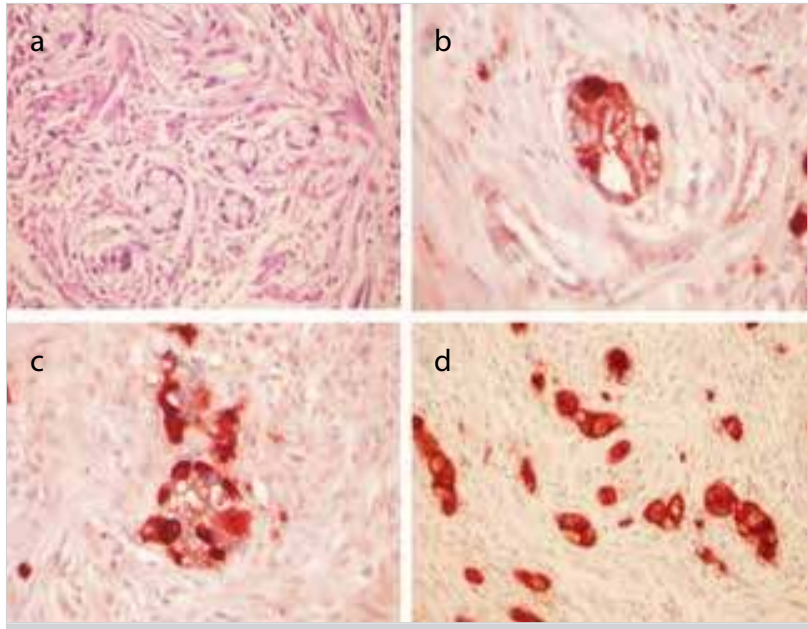

Figure 1. a-d. (a) Adenocarcinoid tumor of goblet cell type. (b) strong immunoreactivity with chromogranin. (c) strong immunoreactivity with synaptophysin. (d) strong immunoreactivity with CEA

observed in the microscopic examination. The size of the tumor was $1 \mathrm{~cm}$. The tumor was composed of either single cell infiltrations or groups of four to five cells that were larger than normal goblet cells, with mild atypia (Figure 1). Perineural invasion was detected. Diffuse positivity of the tumor cells was determined by Alcian blue/PAS staining. Immunohistochemical analysis revealed strong diffuse positivity between the tumor cells as well as positive chromogranin, synaptophysin, and CEA results (Figure 1). Sustentacular cells between S-100 and cell nests were observed to be positive. The patient healed uneventfully and was discharged on the postoperative fifth day. After a twelve-month follow-up period, recurrence was not observed. The patient signed an informed consent form to participate in this study.

\section{DISCUSSION}

Malign tumors of the appendix are rare and are seen at a rate of $0.5 \%-1.4 \%$ following appendectomies (10). While the most common neoplasia of the appendix is carcinoid tumor, the appendix is the most common localization of carcinoid tumors. Adenocarcinoma is the second most common appendix neoplasia (1). GCC constitutes less than $5 \%$ of all carcinoid tumors of the appendix (7). These tumors present both endocrine and glandular differentiations; therefore, they demonstrate both epithelial and carcinoid tumor attributes (11). Various theories have been proposed on the histological origin of GCC (12, 13). In 1979, Warner et al. (13) described GCC as a neoplasm of endodermal origin arising from root cells located in the basal part of the gland and crypta. Ratzenhofer et al. (14) defined this tumor as an amphicrine neoplasm (endo-exocrine) in 1980 . Some studies showed that $\mathrm{p} 53$ gene mutation plays an important role in the pathogenesis of GCC. Another remarkable genetic factor of GCC is the frequent loss of alleles in chromosomes 11q, 16q, and 18q (15).

Goblet cell carcinoids are usually accompanied by acute appendicitis symptoms and findings (8). They can also be detected incidentally during surgery that is performed for other organ diseases. These tumors rarely compose a discrete mass; therefore, they can be diagnosed only by postoperative histological analysis (6). Abnormal thickening of the appendix wall or deposition of mucinous material in its lumen are determinative signs for GCC (16). Luminal stenosis develops due to the circumferential involvement of the appendiceal wall, with longitudinal extension.

Goblet cell carcinoid tumors manifest more aggressive behavior than other carcinoid tumors. The metastasis rate of appendix carcinoids is $2 \%-5 \%$, while it is $15 \%-30 \%$ for GCCs (4). Carcinoembriyonic antigen (CEA) has been found to be increased in metastatic cases (11). GCC can cause various complaints, such as abdominal mass, mesenteric lymphadenitis, and gastrointestinal bleeding $(8,9,17)$. These tumors may rarely lead to pseudomyxoma peritonei, similar to other mucinous tumors. Appendix goblet cells secrete MUC2 and MUC5AC. MUC2 measurement is a specific indicator in the case of psesudomyxoma peritonei related to appendix GCC (18). There are rare cases in the literature regarding GCC tumors accompanied by Krukenberg tumors or colorectal adenocarcinoma $(19,20)$. In our case, right hemicolectomy was performed due to a sessile polyp of the cecum with high grade dysplasia; GCC of the appendix was later diagnosed coincidentally.

The clinical behavior of GCC tumors can vary; therefore, there are still controversial issues regarding both evaluating the malignant potential of the tumor and choosing an appropriate treatment. The initial reports regarding treatment options for GCC recommended appendectomy as an adequate treatment. Then, Varisco et al. (21) emphasized that appendectomy is adequate in the case of low-grade tumor histology without involvement of the cecum. Conversely, some authors suggest the necessity of right hemicolectomy because of the unpredictable behavior of GCC (9). While appendectomy is adequate for most patients, more radical approaches may be required in cases that present more complicated profiles, such as diffuse appendix involvement, tumor size greater than $2 \mathrm{~cm}$, cellular undifferentiation, increased mitotic activity, presence of cecal wall involvement, or lymph node metastasis $(3,6)$. Due to the high risk of metastasis to the ovaries in female cases, bilateral oophorectomy is recommended in addition to right hemicolectomy (19). In our case, the tumor was $1 \mathrm{~cm}$ in diameter. Furthermore, perineural invasion and periappendicular expansion with involvement of all layers of the appendiceal wall were determined.

Goblet cell carcinoids do not form distinctive tumoral tissue; therefore, surgical resection borders in the appendectomy specimen should be examined microscopically in detail. To differentiate GCC from standard appendix carcinoid tumors, measurement of the amount of mucin production can be useful. The presence of a few amin precursor uptake decarboxylase (APUD) cells and positive staining of tumor cells with lysozyme and $\lg \mathrm{A}$ are the other differentiating attributes (12).

Metastasis occurs in nearly $20 \%$ of GCC tumors, and the ovarium is the most common metastatic site for GCC (21). Studies revealed the presence of distant metastasis in $11.2 \%$ of patients and lymph involvement in $8.7 \%$ of patients during diagnosis (22). Intraperitoneal chemotherapy should be provided to patients if GCC is accompanied by peritoneal carcinomatosis. Intraperitoneal chemotherapy is also recommended if the tumor tissue is perforated during the surgery. Among metastatic GCC cases, survival rates are higher in patients who 
received intraperitoneal chemotherapy than in patients who underwent surgery alone (23). Ovarian, lymphatic, and distant metastasis were not detected in our patient after a 12-month follow-up period. Marked octreotide scintigraphy is the most sensitive imaging method for diagnosis and follow-up of GCC. Plasma chromogranin $A$ is also known as a hematological indicator for GCC. Thus, plasma chromogranin A and 5-hydroxyindoleacetic acid (5-HIAA) should be tested in a 24-hour urine sample, and marked octreotide scintigraphy should be performed in the follow-up period (9).

Goblet cell carcinoid tumors are located between carcinoid tumors and well-differentiated adenocarcinomas in terms of prognosis (6). The most important prognostic factor is the stage of the tumor (22). However, discussion regarding tumor size is controversial because tumors do not always form a significant mass (6). Metastasis to the ovaries and expansion into the abdominal cavity influence the prognosis very negatively. The five-year survival rate of GCC tumors was determined to be $60 \%$ to $84 \%$, and the recurrence rate was found to be $16 \%$ $(11,15)$.

\section{CONCLUSION}

Goblet cell carcinoid should always be considered as a differential diagnosis in patients with suspected appendicitis with or without a mass formation. In cases of appendectomy due to appendicitis or other intra-abdominal pathologies, detailed histological examination of the appendectomy specimen is very important, especially for older patients, to not miss appendicular tumors that could be asymptomatic but aggressive.

Informed Consent: Written informed consent was obtained from patient who participated in this study.

Peer-review: Externally peer-reviewed.

Author Contributions: Concept - İ.A.Ö., R.Y., O.A.; Design - I.A.Ö., E.Z., H.B.; Supervision - I.A.Ö., R.Y., O.A.; Resource - I.A.Ö., E.Z., C.B.; Materials - I.A.Ö., E.Z., C.B.; Data Collection and/or Processing - I.A.Ö., E.Z., C.B.; Analysis and/or Interpretation - I.A.Ö., H.B., O.A.; Literature Search - A.Ö., H.B., C.B.; Writing Manuscript - A.Ö., E.Z., C.B.; Critical Reviews I.A.Ö., R.Y., O.A .

Conflict of Interest: The authors have no conflicts of interest to declare.

Financial Disclosure: The authors declared that this study has received no financial support.

\section{REFERENCES}

1. McCusker ME, Cote TR, Clegg LX, Sobin LH. Primary malignant neoplasms of the appendix: a population-based study from the surveillance, epidemiology and end-results program, 1973-1998. Cancer 2002; 94: 3307-3312. [CrossRef]

2. Rodriguez FH Jr, Sarma DP, Lunseth JH. Goblet cell carcinoid of the appendix. Hum Pathol 1982; 13: 286-288. [CrossRef]

3. Horiuchi S, Endo T, Shimoji H, Takahashi H, Mitsuuchi M, Yawata A, et al. Goblet cell carcinoid of the appendix endoscopically diag- nosed and examined with p53 immunostaining. J Gastroenterol 1998; 33: 582-587. [CrossRef]

4. Gallegos NC, Milroy C, Linehan IP, Boulos PB. Crypt cell carcinoma of the appendix. Eur J Surg Oncol 1992; 18: 386-387.

5. Tang LH, Shia J, Soslow RA, Dhall D, Wong WD, O'Reilly E, et al. Pathologic classification and clinical behavior of the spectrum of goblet cell carcinoid tumors of the appendix. Am J Surg Pathol 2008; 32: 1429-1443. [CrossRef]

6. Butler JA, Houshiar A, Lin F, Wilson SE: Goblet cell carcinoid of the appendix. Am J Surg 1994; 168: 685-687. [CrossRef]

7. Roy P, Chetty R. Goblet cell carcinoid tumors of the appendix: An overview. World J Gasrointest Oncol. 2010; 2: 251-258. [CrossRef]

8. Pickhardt PJ, Levy AD, Rohrmann CA Jr, Kende Al. Primary neoplasms of the appendix: radiologic spectrum of disease with pathologic correlation. Radiographics 2003; 23: 645-662. [CrossRef]

9. Goede AC, Caplin ME, Winslet MC. Carcinoid tumor of the appendix. Br J Surg 2003; 90: 1317-1322. [CrossRef]

10. Connor SJ, Hanna GB, Frizelle FA. Appendiceal tumors: retrospective clinicopathologic analysis of appendiceal tumors from 7970 appendectomies. Dis Colon Rectum 1998; 41: 75-80. [CrossRef]

11. Carr NJ, Remotti H, Sobin LH. Dual carcinoid/epithelial neoplasia of the appendix. Histopathology 1995; 27: 557-562. [CrossRef]

12. IsaacsonP. Crypt cell carcinoma of the appendix (so-called adenocarcinoid tumor). Am J Surg Pathol 1981; 5: 213-214. [CrossRef]

13. WarnerTF, SEo IS: Goblet cell carcinoid of appendix: ultrastructural features and histogenetic aspects. Cancer 1979; 44: 1700-1706. [CrossRef]

14. Ratzenhofer M, Aubock $L$. The amphicrine (endo-exocrine) cells in the human gut, with a short reference to amphicrine neoplasias. Acta Morphol Acad Sci Hung 1980; 28: 37-58.

15. Stancu M, Wu TT, Wallace C, Houlihan PS, Hamilton SR, Rashid A. Genetic alterations in goblet cell carcinoids of the vermiform appendix and comparison with gastrointestinal carcinoid tumors. Mod Pathol 2003; 16: 1189-1198. [CrossRef]

16. Kuroda N, Mizushima S, Guo L, Jin Y, Tao L, Miyazaki E, et al. Goblet cell carcinoid of the appendix: Investigation of the expression of beta-catenin and Ecadherin. Pathol Int 2001; 51: 283287. [CrossRef]

17. Anderson $\mathrm{NH}$, Somerville JE, Johnston $\mathrm{CF}$, Hayes DM, Buchanan KD, Sloan JM. Appendiceal goblet cell carcinoids: a clinico-pathological and immunohistochemical study. Histopathology 1991; 18: 61-65. [CrossRef]

18. Larsen SG, Nilssen A, Helseth A, Bohler P, Giercksky KE. Invagination of the appendix with carcinoid tumor. Eur J Surg 1999; 165: 993-997. [CrossRef]

19. Mandai M, Konishi I, Tsuruta Y, Suginami N, Kusakari T, Iwasaki T, et al. Krukenberg tumor from an occult appendiceal adenocarcinoid: a case report and review of the literature. Eur J Obstet Gynecol Reprod Biol 2001; 97: 90-95. [CrossRef]

20. Gravante G, Yahia S, Gopalakrishnan K, Mathew G. Goblet cells carcinoid with mucinous adenocarcinoma of the vermiform appendix: a step towards the unitary intestinal stem cell theory? Eur Rev Med Pharmacol Sci 2014; 18: 1591-1594.

21. Varisco B, McAlvin B, Dias J, Franga D. Adenocarcinoid of the appendix: is right hemicolectomy necessary? A meta-analysis of retrospective chart reviews. Am Surg 2004; 70: 593-599.

22. Pahlavan PS, Kanthan R. Goblet cell carcinoid of the appendix. World J Surg Onc 2005; 3: 36. [CrossRef]

23. Mahteme H, Sugarbaker PH. Treatment of peritoneal carcinomatosis from adenocarcinoid of appendiceal origin. Br J Surg 2004; 91: 1168-1173. [CrossRef] 